\title{
Imaging of the sublingual and submandibular spaces
}

\author{
Swapnil Patel ${ }^{1} \cdot$ Alok A. Bhatt $^{1}$ \\ Received: 16 October 2017 / Revised: 19 February 2018 / Accepted: 1 March 2018 / Published online: 19 April 2018 \\ (C) The Author(s) 2018
}

\begin{abstract} distinguishing imaging features necessary for accurate characterisation.

\section{Teaching Points}

- The mylohyoid sling is a key anatomical landmark useful in surgical planning.

- Congenital lesions and infectious/inflammatory processes constitute the majority of pathology.

- Depth of invasion is key when staging tumours in the oral cavity.
\end{abstract}

Divided by the mylohyoid muscle, the sublingual and submandibular spaces represent a relatively small part of the oral cavity, but account for a disproportionate amount of pathological processes. These entities are traditionally separated into congenital, infectious/inflammatory, vascular and neoplastic aetiologies. This article reviews the relevant anatomy, clinical highlights and

Keywords Head and neck $\cdot$ Salivary glands $\cdot$ Education $\cdot \mathrm{CT} \cdot \mathrm{MR}$

\section{Introduction}

The suprahyoid neck is frequently the site of many common conditions. Although accessible to clinical exam, some components are better evaluated with imaging; lesions occupying the sublingual space and submandibular space are invisible to the referring clinician. A broad array of pathological processes can occur in these spaces and pinpointing the origin can narrow the differential and in certain cases determine the diagnosis. These lesions can be classified into congenital, infectious/inflammatory, vascular and neoplastic processes. Typically, computed tomography (CT) or magnetic resonance imaging (MRI) are used for evaluation, but there may be cases where both are needed in conjunction. This review article discusses the relevant anatomy, clinical highlights and the characteristic imaging features of the various pathologies that occur within the sublingual and submandibular spaces.

Alok A. Bhatt

alok_bhatt@urmc.rochester.edu

1 Department of Imaging Sciences, University of Rochester Medical Center, 601 Elmwood Avenue, P.O. Box 648, Rochester, NY 14642, USA

\section{Embryology/anatomy}

Within the suprahyoid neck, the sublingual and submandibular spaces are the site of a large variety of pathology, given their embryological origin and contents [1].

The sublingual space is bounded anteriorly by the mandible, medially by the midline genioglossus/geniohyoid muscle complex, inferolaterally by the mylohyoid muscle, and superomedially by the mucosa of the floor of the mouth and intrinsic tongue muscles (Figs. 1 and 2). Communication of the right and left sublingual space occurs anteriorly under the frenulum of the tongue [1].

Although predominantly fat-containing, the sublingual space also contains the sublingual gland and duct, a portion of the hyoglossus muscle, the lingual artery and vein, lingual nerve (branch of $\mathrm{CN} V$ ), branches of the glossopharyngeal (CN IX) and hypoglossal (CN XII) nerves, as well as the deep portion of the submandibular gland and duct [2].

The submandibular space is bounded anteriorly and laterally by the mandible, medially by the anterior belly of the digastric muscles, superiorly by the mylohyoid muscle and inferiorly by the hyoid bone (Figs. 1 and 2). The space is enclosed by the superficial layer of the deep cervical fascia, except along the posterior margin of the mylohyoid muscle, permitting continuity with the sublingual space and potential communication with the parapharyngeal 


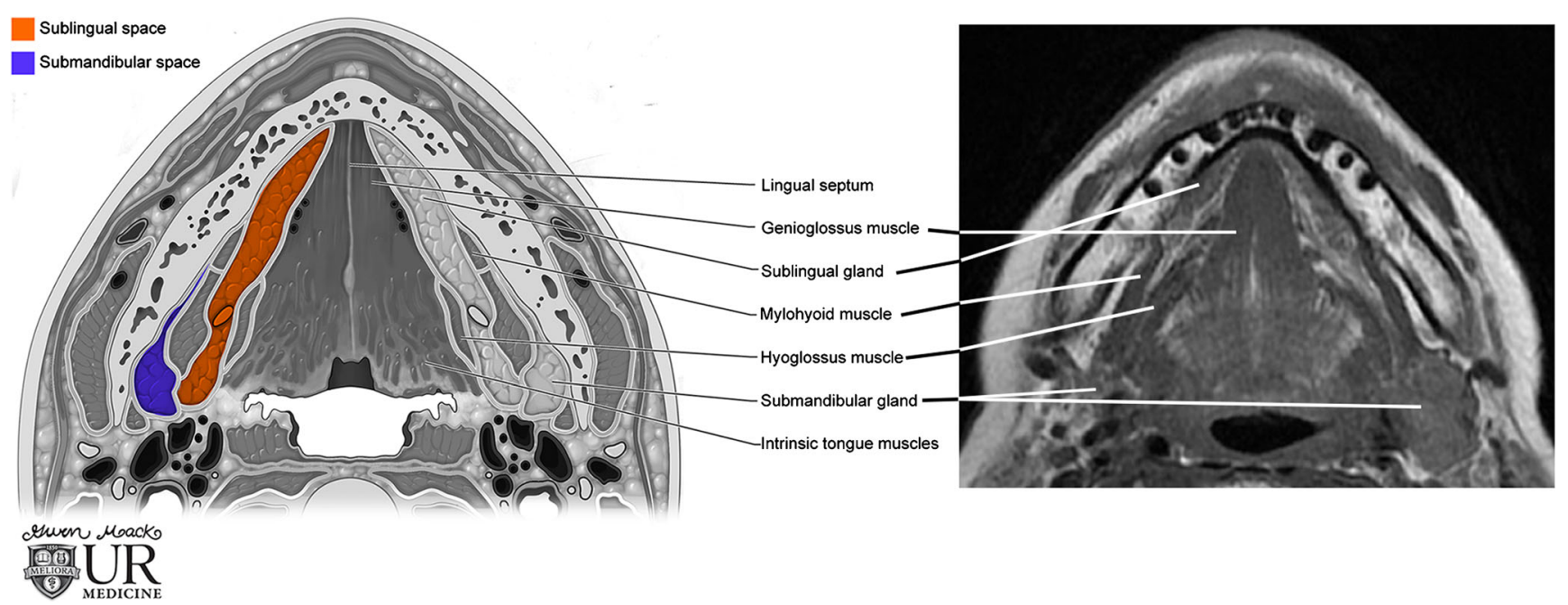

Fig. 1 Anatomy of the submandibular and sublingual spaces in the axial plane: picture illustration and T1-weighted MR image

space through a buccopharyngeal gap created by the styloglossus muscle. The primary contents include the superficial portion of the submandibular gland, submandibular lymph nodes and fat. The facial artery and vein, as well as a portion of the hypoglossal nerve, course through the space [2].

\section{Pathology}

A variety of disease processes occur in the sublingual and submandibular spaces, and can be broadly classified into congenital, infectious, vascular and neoplastic aetiologies (Table 1). CT and MRI are the modalities of choice for imaging this region; CT is readily available, and MRI provides superior soft tissue resolution. Other commonly used modalities such as ultrasound, conventional sialography and positron emission tomography (PET) will be presented in order to illustrate findings on different modalities; often, pathology of these spaces may be discovered on exams performed for other reasons.

\section{Congenital}

\section{Aplasia/hypoplasia of salivary glands}

Aplasia of the salivary glands is a rare condition that usually affects the parotid and submandibular glands. Single or multiple glands may be absent or hypoplastic. Exact aetiology

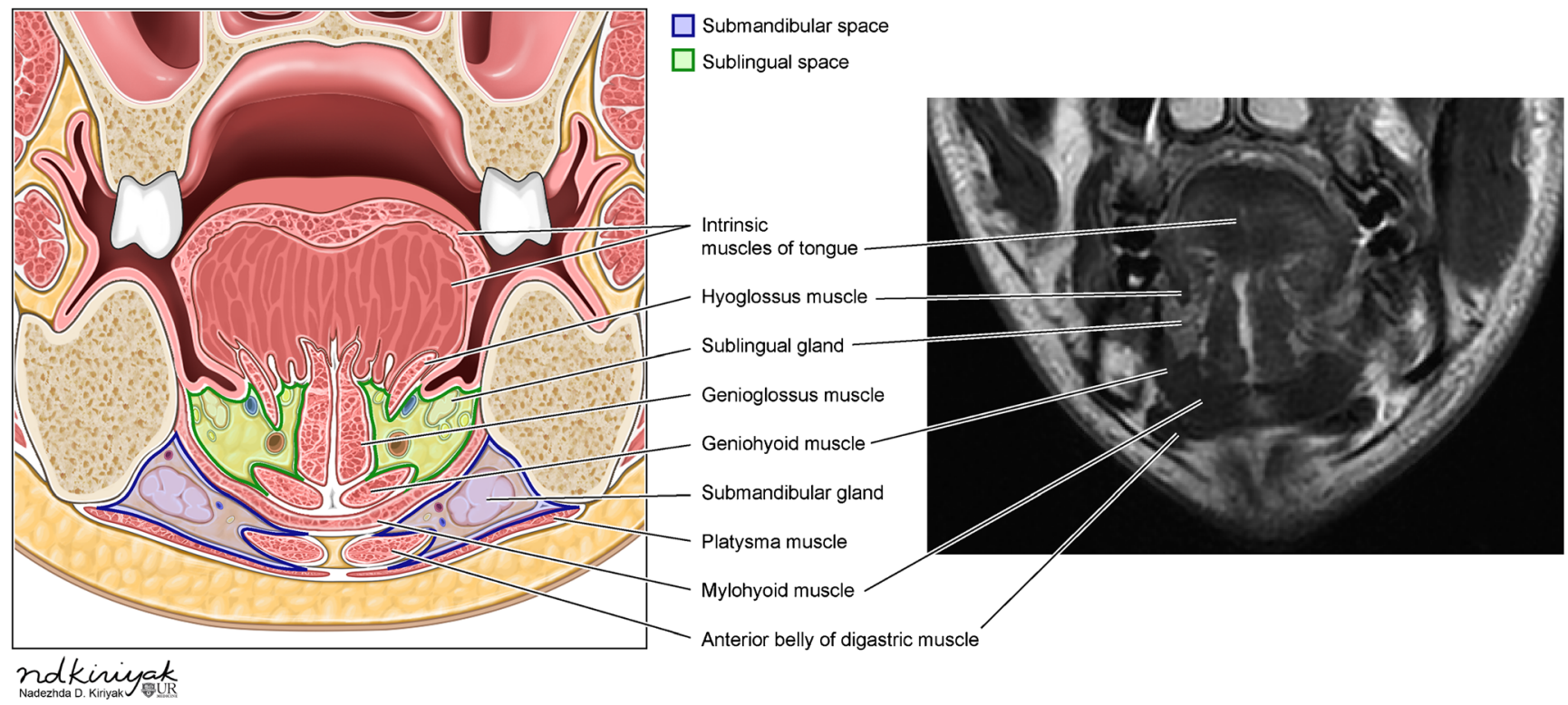

Fig. 2 Anatomy of the submandibular and sublingual spaces in the coronal plane: picture illustration and T2-weighted MR image 
Table 1 Categorisation of spectrum of pathology

\begin{tabular}{llll}
\hline Congenital & Vascular & Infection/inflammation & Neoplasm \\
\hline Aplasia/hypoplasia of salivary glands & Low flow & Cellulitis & Benign \\
& -Venous malformations & Ludwig angina & -Lipoma \\
Dermoid/Epidermoid cyst & -Lymphatic malformations & Abscess & Ranula \\
& & (ie. pleomorphic adneoma) & -Neurogenic tumours \\
& High flow & Malignant \\
& -Arterial malformations & Sialoadenitis & -Squamous cell carcinoma \\
& & & -Primary salivary gland tumours \\
(ie. mucoepidermoid carcinoma) & -Lymphoma
\end{tabular}

remains unknown; however, the condition has been attributed to first and second branchial arch abnormalities. Specifically, it has been associated with genetic syndromes involving craniofacial development such as Treacher-Collins syndrome, hemifacial microsomia and lacrimo-auriculo-dento-digital syndrome [3]. Some studies report increased incidence in trisomy 21 [4]. Although usually discovered incidentally on imaging, some cases are identified when patients present with dry mouth, dysphagia and dental disease. Imaging may show compensatory hypertrophy of other major salivary glands, and therefore it is important not to mistake normal gland tissue for other lesions such as tumour [5].

\section{Dermoid and epidermoid cysts}

True dermoid cysts (also known as benign cystic teratomas), epidermoid cysts and teratoid cysts represent a spectrum of congenital and acquired cystic malformations sharing the common characteristic of a squamous epithelial lining. Dermoid cysts as a term refers to three histologically distinct processes classified based on whether they are lined with simple

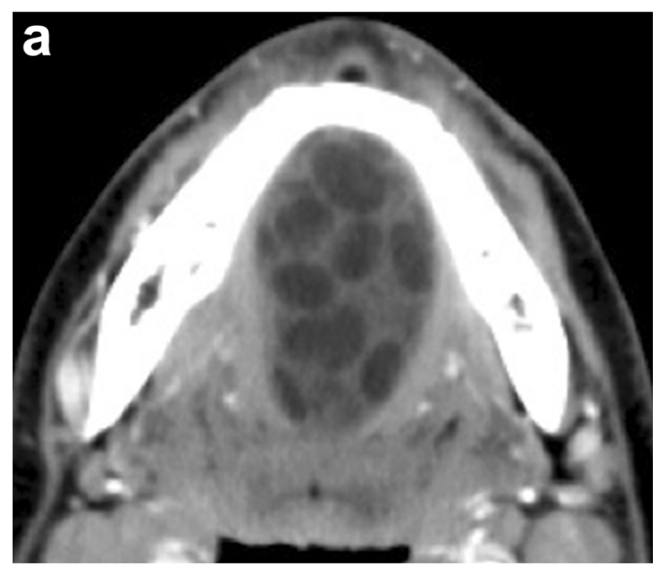

Fig. 3 Dermoid cyst. Axial contrast-enhanced CT image shows a lesion with globules of fat ("sac of marbles") in a fluid medium splaying the genioglossus muscles laterally to their respective ipsilateral sides squamous epithelium (epidermoid), skin appendages (dermoid) or tissues of other major organs (teratoid). Dermoids and epidermoids arise from dermal elements of the first and second branchial arches [1, 6]. It is important to distinguish dermoid and epidermoid cysts apart from teratoid cysts, as the former harbour a lower risk of malignant degeneration [7]. Although rare within the head and neck, dermoid and epidermoid cysts have a predilection for the oral cavity, specifically the floor of the mouth [8]. Dermoid cysts typically present in the 2nd or 3rd decade of life as a slowly enlarging midline neck mass, which may progress to cause dysphagia, while epidermoid cysts manifest earlier in life, becoming evident in infancy.

On imaging, dermoid and epidermoid cysts can have a similar appearance. Some of the distinguishing features are derived from their unique histological composition. While both behave as cystic lesions on CT and MRI, dermoid cysts will demonstrate the hallmark finding of coalesced globules of fat resembling a "sac of marbles" in a medium (mixture of accessory dermal contents such as sebum and calcification) of low CT attenuation and variable signal on T1-weighted images (Figs. 3 and 4) [9]. Epidermoid cysts will distinctively show diffusion restriction on MRI [10]. The relationship of

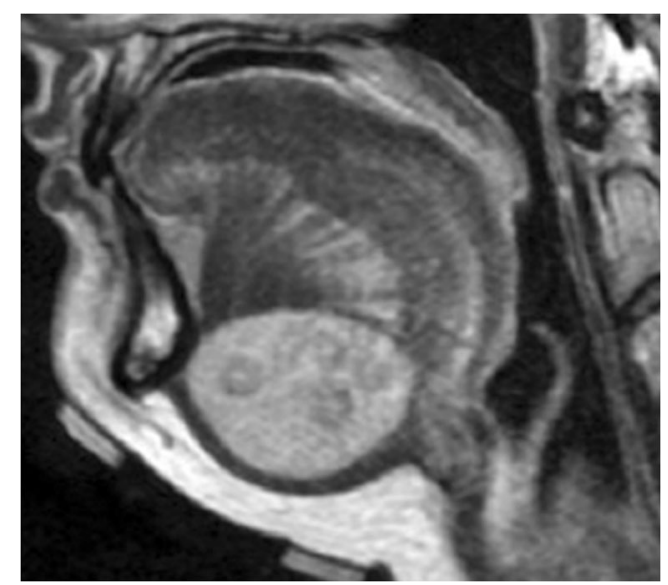

Fig. 4 Dermoid cyst. Sagittal T2-weighted MR image shows a wellcircumscribed cystic lesion filled with fat globules ("sac of marbles") 
Table 2 Distinguishing imaging features among cystic lesions in the sublingual and submandibular spaces

\begin{tabular}{|c|c|c|c|}
\hline & Ranula & Dermoid & Epidermoid \\
\hline $\mathrm{CT}$ & -Well circumscribed cyst & $\begin{array}{l}\text {-Mixed cystic and solid } \\
\text {-May contain calcifications }\end{array}$ & $\begin{array}{l}\text {-Well circumscribed cyst } \\
\text {-No distinct solid } \\
\text { component }\end{array}$ \\
\hline MR & $\begin{array}{l}\text {-Fluid signal with variable } \mathrm{T} 1 \text { signal } \\
\text { (proteinaceous contents) }\end{array}$ & $\begin{array}{l}\text {-Fat globules with "sack of marbles" appearance } \\
\text {-Heterogenous signal due to dermal elements and cystic } \\
\text { composition }\end{array}$ & -Diffusion restriction \\
\hline Site & $\begin{array}{l}\text {-Typically associated with the salivary } \\
\text { glands, commonly sublingual gland } \\
\text {-May extend into submandibular space } \\
\text { (plunging ranula) }\end{array}$ & $\begin{array}{l}\text {-Most commonly in the floor of the mouth, specifically } \\
\text { within the sublingual and submandibular spaces }\end{array}$ & $\begin{array}{l}\text {-Most commonly in the } \\
\text { floor of the mouth }\end{array}$ \\
\hline Histology & -Resemble mucous retention cyst & $\begin{array}{l}\text {-Presence of skin appendages (hair, sebaceous glands, } \\
\text { sweat glands) }\end{array}$ & -Lack of skin appendages \\
\hline
\end{tabular}

these cystic lesions to the mylohyoid muscle is important in guiding surgical intervention, as cysts superior to the mylohyoid muscle are removed preferably with an intraoral approach, while inferior lesions are excised through an external submandibular approach [11].

\section{Infectious/inflammatory}

There are many causes, as well sequelae of inflammation and infection within the sublingual and submandibular spaces. Proper localisation of the abnormality is useful in determining aetiology.

\section{Ranula}

Among the differential diagnosis of cystic lesions in the sublingual space, a ranula is a commonly acquired lesion (Table 2). Traditionally considered as a post-inflammatory or post-traumatic sequela of glandular obstruction, a ranula is a mucous retention cyst arising from the sublingual or minor salivary glands [12].
On imaging, ranulas have the typical appearance of cystic lesions with fluid attenuation on CT, hyperintensity on T2weighted MR sequences, and are anechoic on ultrasound (Fig. 5). MRI in particular can serve to assess the size, content, location and extent of the lesion, especially in preoperative planning [13]. Additionally, a ranula can be indistinguishable from an epidermoid cyst based on CT and sonography, but the absence of restricted diffusion on MRI establishes the diagnosis (Fig. 6) [14].

As the cystic lesion enlarges, it can "rupture" through its sublingual space boundaries and extend into the submandibular space through the posterior free edge of the mylohyoid muscle or mylohyoid boutonniere. Referred to as a plunging ranula, the herniated portion leaves behind a band-like portion of the cyst within the sublingual space, forming the "tail sign" (Fig. 7) [15]. On rare occasions, it can also extend into the parapharyngeal space or upper cervical soft tissues [16].

\section{Cellulitis/abscess}

Cellulitis is a diffuse infectious process of the skin and subcutaneous tissues. In the oral cavity, infections typically
Fig. 5 Simple ranula. a Axial and b coronal contrast-enhanced CT images demonstrate a wellcircumscribed fluid attenuation lesion within the left sublingual space $(*)$
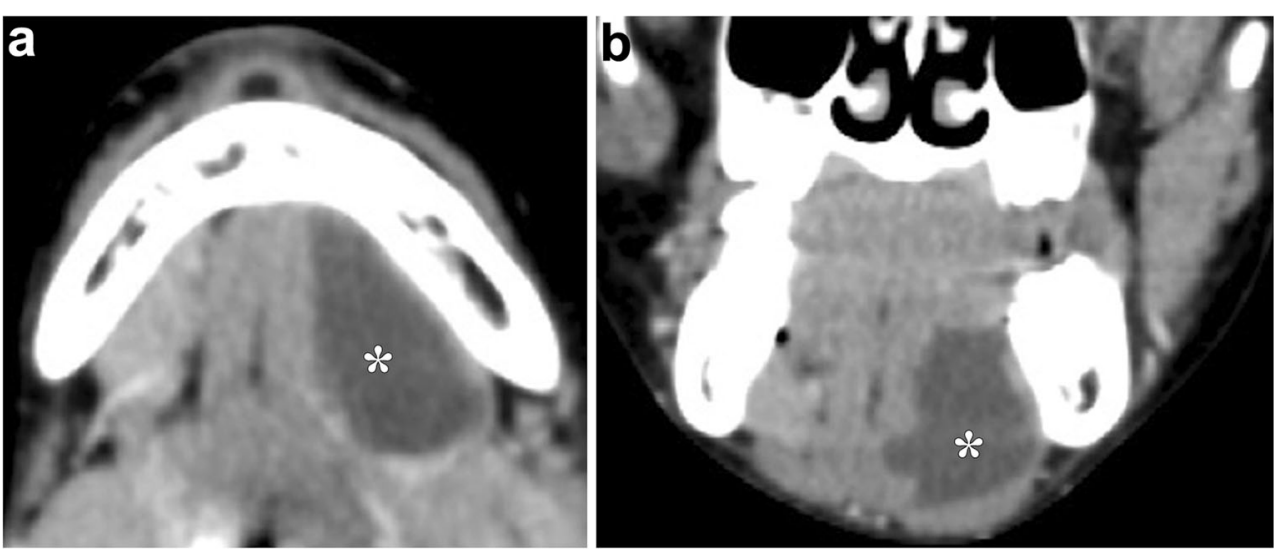


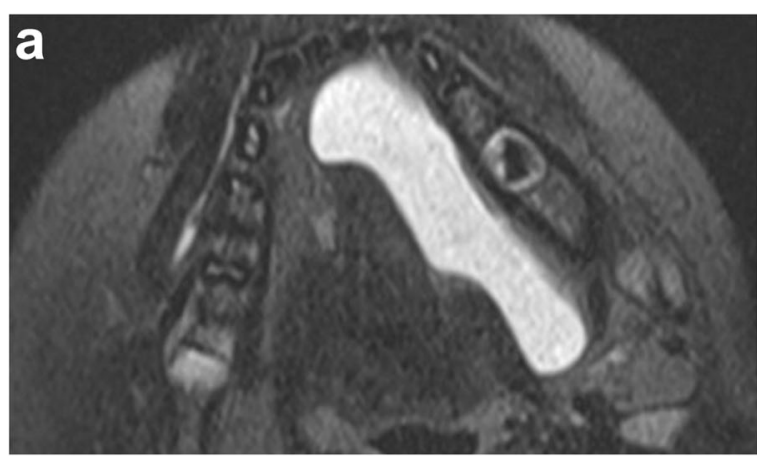

Fig. 6 Sublingual space ranula. a Axial T2-weighted MR image shows a high-signal lesion within the left sublingual space. b Axial diffusionweighted image and $\mathbf{c}$ ADC map demonstrates lack of restricted
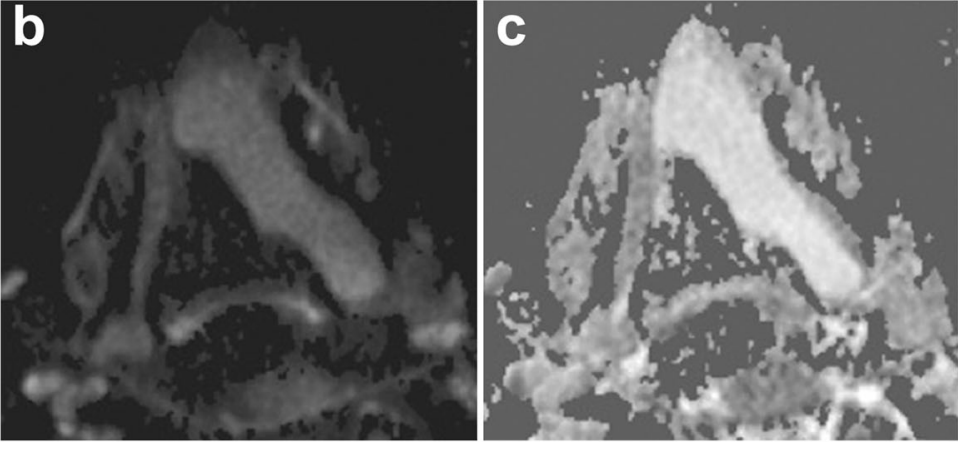

diffusion, confirming the diagnosis (as opposed to an epidermoid, which would have restricted diffusion)

of gas-forming bacteria. Allowing for rapid evaluation, CT is preferred, which will show diffuse inflammatory changes and bands of fluid, representative of serosanguinous accumulations [19]. As a multispatial process, extension into the parapharyngeal fat/space increases the likelihood of pharyngeal involvement with significant increased risk of impending airway collapse and mediastinitis (Fig. 9). Clinical management involves prompt airway protection, intravenous antibiotic administration and surgical drainage [20].

\section{Sialadenitis and sialolithiasis}

Salivary stones (sialoliths) represent calcium concretions, most commonly within the submandibular ductal system, owing to the relatively higher calcium and phosphate salt concentrations of the gland's secretions [21]. The resultant inflammation clinically manifests as glandular tenderness and swelling, particularly after meals. Sialadenitis is best evaluated with CT, which will show increased size and density of the gland, with ductal calcifications; post-contrast imaging will show diffuse, intense enhancement (Fig. 10) [2]. Advanced stages of sialadenitis can present with suppurative infections and abscess formation $[22,23]$. The differential diagnosis of
Fig. 7 Plunging ranula. Axial contrast-enhanced CT images of the floor of the mouth illustrates a well-circumscribed cystic lesion predominantly occupying the left submandibular space causing a mass effect on the left

submandibular gland (a, arrow). A more superior image reveals a small portion of the lesion based in the sublingual space, referred to as the "tail sign" (b, arrowheads)
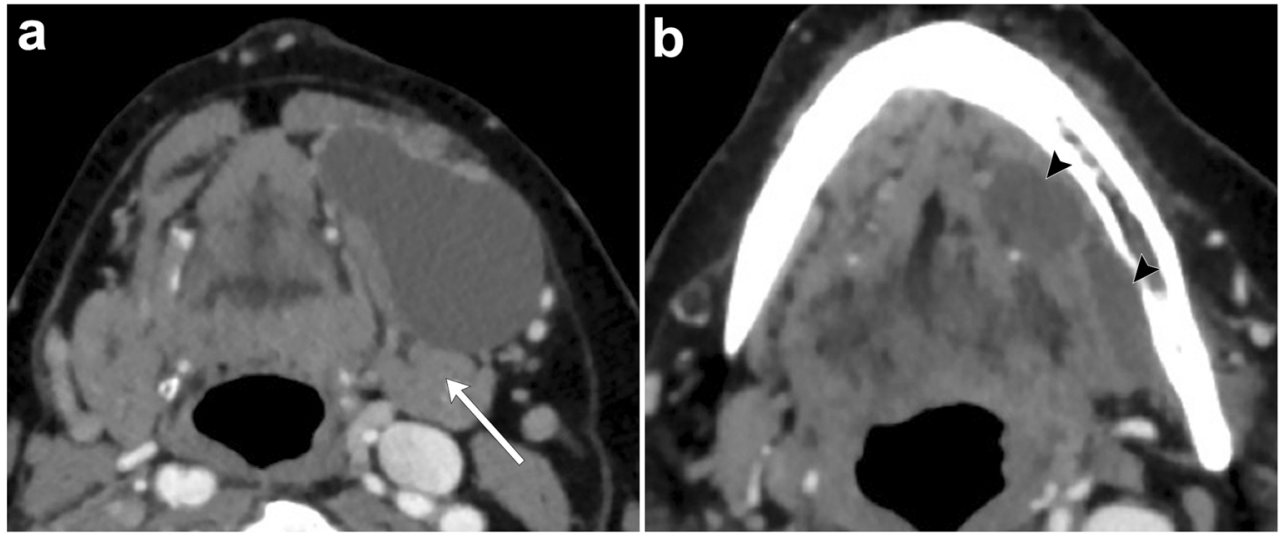


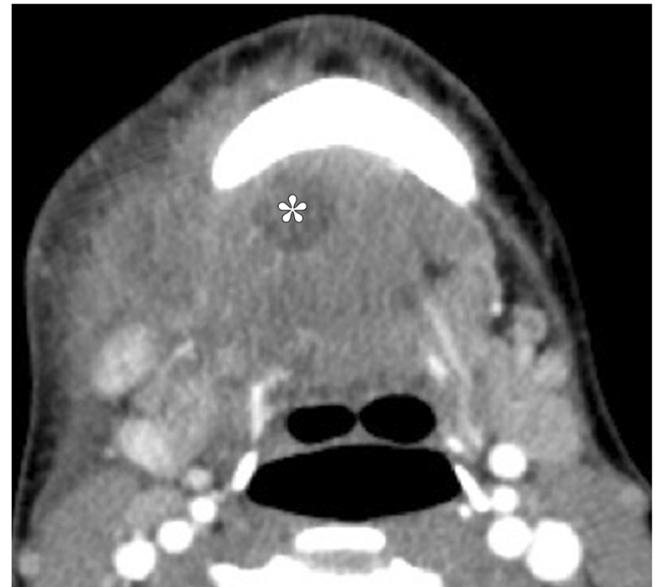

Fig. 8 Sublingual/submandibular space abscess. Axial contrast-enhanced CT image through the floor of the mouth demonstrates extensive subcutaneous fat stranding and inflammatory changes centred within the right submandibular and sublingual spaces. A well-circumscribed fluid-attenuating collection is present within the right sublingual space consistent with early abscess formation (*)

abscess within the salivary glands includes superinfected cysts in HIV patients, suppurative and necrotic lymph nodes, and cystic degeneration of malignancy; therefore, clinical context must be reviewed carefully, and follow-up to resolution may be warranted [22].

Ductal obstruction and calculi as small as $3 \mathrm{~mm}$ can be detected on ultrasound, although it is operator dependent [24]. Sialography is the reference standard imaging modality, as it can demonstrate ductal obstruction from multiple aetiologies, including recurrent infection, autoimmune processes and trauma (Fig. 11). MRI and conventional digital subtraction sialography have been found to be comparable in diagnostic performance [25].

\section{Vascular}

Although vascular malformations commonly occur in the head and neck, they are rare within the sublingual and submandibular spaces. Congenital in nature, these lesions are present at birth, but are discovered later in life as they grow with the patient. They are classified based on the primary constituent channel and rate of flow, with resulting distinctive imaging characteristics (Table 3). Slow-flow lesions consist of lymphatic, venous and venolymphatic networks, while highflow lesions exploit an arteriovenous communication. Initial evaluation may be performed with ultrasound; however, complete characterisation requires CT or MRI [26].

\section{Low-flow lesions}

Characterised by slow vascular flow, this category predominantly consists of venous-based lesions or venous malformations, which most frequently involve the floor of the mouth or buccal space when they occur in the head and neck [13]. Histologically, they are composed of a mass-like collection of venous sinusoids. On initial evaluation, typically by ultrasound, they appear as compressible mixed echogenicity structures with ill-defined margins and monophasic low velocity flow on Doppler interrogation. CT and MRI are used to evaluate spatial extent, visceral involvement and osseous destruction [27]. On MRI, signal patterns depend on vessel size and range from hyperintense venous lakes to more solid appearing lesions that are isointense to muscle on T2-weighted imaging. CT attenuation follows a similar pattern [13]. Characteristic features of any venousbased anomaly, such as phleboliths or diffuse venous phase enhancement, are also present [1].

Infantile haemangiomas are vascular tumours, rather than malformations, as they exhibit a distinct life cycle: manifest in infancy with initial rapid growth and proliferation, followed by involution in early childhood. Clinical presentation is usually sufficient in diagnosis without imaging assistance [1].

Contributing to the slow flow spectrum, lymphatic malformations, also known as lymphangiomas, are cystic structures with partial enhancement and more commonly occur in the submandibular space. Characteristic appearance is that of a non-enhancing multiloculated cystic lesion with fluid-fluid levels without phleboliths [18]. Unilocular lesions are less common and may be mistaken for a thyroglossal duct cyst or duplication cyst [10].
Fig. 9 Ludwig angina. a Axial and $\mathbf{b}$ sagittal contrast-enhanced CT images show diffuse inflammatory changes with bands of fluid within the submandibular and sublingual spaces. These changes extend posteriorly into bilateral parapharyngeal spaces, pharyngeal mucosa, and inferiorly along the anterior neck (b)
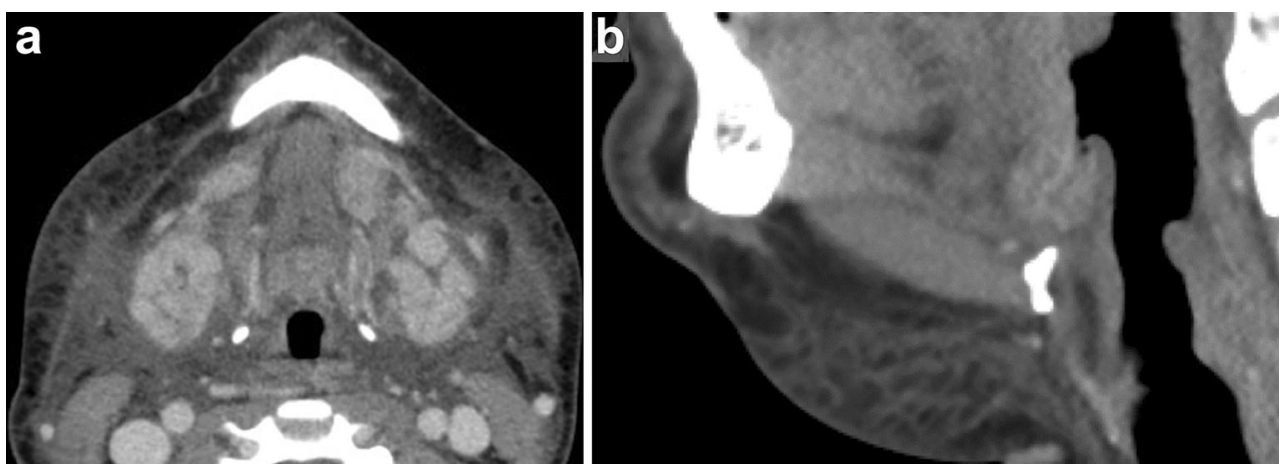
Fig. 10 Sialolithiasis with resultant sialadenitis. Axial contrast-enhanced CT images at the level of the submandibular gland demonstrate two wellcircumscribed calcifications in the distal right submandibular duct (a, arrow). The right submandibular duct is dilated proximal to the stones $(\mathbf{b}$, arrowhead). There is enlargement and enhancement of the right submandibular gland $(*)$ compared to the normal left submandibular gland
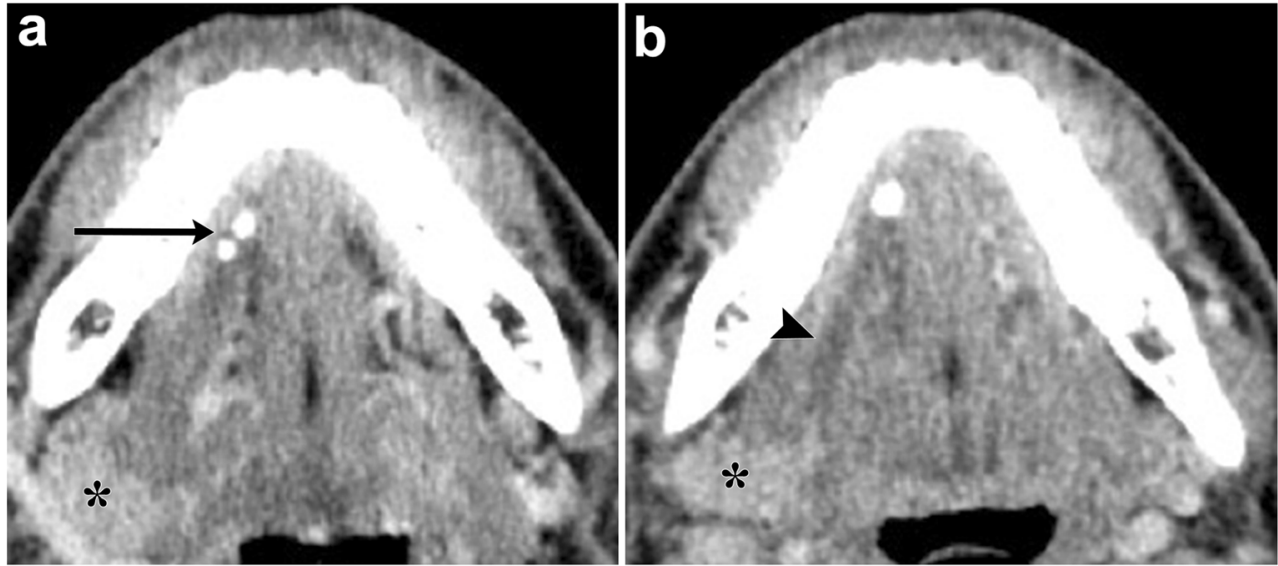

Mixed veno-lymphatic lesions share imaging features of both venous and lymphatic malformations, namely high signal on T2-weighted imaging attributed to the lymphatic component and homogenous enhancement attributed to the venous component (Fig. 12) [10].

\section{High-flow lesions}

Arteriovenous malformations (AVMs) may present at any age and largely involve the lingual artery and vein when they occur in the sublingual space. The lesion is characterised on imaging by enlarged, tortuous vessels consisting of a prominent feeding artery and a draining vein. Occasionally, these lesions may exhibit intraosseous extension [13].

\section{Benign neoplasms}

\section{Lipoma}

Lipomas are the most common type of mesenchymal tumour; however, they rarely arise within the oral cavity. They are encapsulated mature adipose tissue and can be distinguished from surrounding fat based on the internal architecture, forming a well-circumscribed predominantly fat-containing lesion with fibrous septa on CT and MRI [18]. Lack of calcifications and cystic components distinguishes these lesions from dermoid cysts [13].

\section{Pleomorphic adenoma}

Pleomorphic adenomas are the most common benign primary lesions of the salivary glands, and occur in the parotid, sublingual and submandibular glands, in order of decreasing prevalence [15]. These tumours arise from salivary gland rests and are composed of epithelial, myoepithelial and stromal components. On CT, they usually appear as wellcircumscribed homogenously enhancing masses, which demonstrate high signal on T2-weighted imaging (Fig. 13). As the lesion enlarges, areas of haemorrhage and cystic necrotic changes may develop, thus altering the classic imaging appearance [13]. Rapid growth should raise suspicion for malignant degeneration, which occurs in about $15 \%$ of cases [1]. Early changes are better delineated on MRI, with loss of
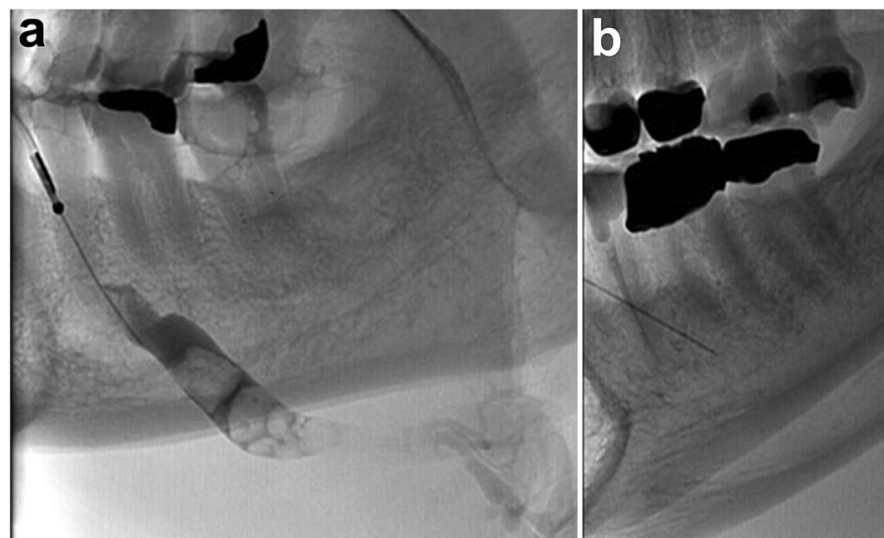

Fig. 11 Sialolithiasis. a Conventional sialogram demonstrates multiple filling defects within Wharton's (submandibular) duct, consistent with sialoliths. b, c In another patient, pre- and post-contrast injection

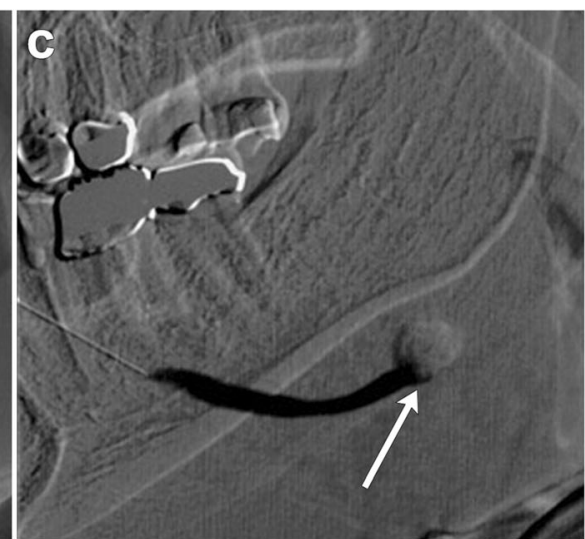

sialogram images demonstrate duct obstruction at the site of a large stone (no contrast is present proximal to the stone, see arrow) 
Table 3 Distinguishing imaging features among vascular malformations of the sublingual and submandibular spaces

\begin{tabular}{|c|c|c|c|}
\hline & Lymphatic & Venous & Arteriovenous \\
\hline $\mathrm{CT}$ & $\begin{array}{l}\text {-Uniloculated or multiloculated cyst } \\
\text { with variably enhancing septa }\end{array}$ & $\begin{array}{l}\text {-Heterogeneous, enhancing infiltrative lesion } \\
\text {-Phlebolith(s) are nearly pathognomic if present }\end{array}$ & -Enlarged artery and vein with shunting \\
\hline MR & $\begin{array}{l}\text {-Uniloculated or multiloculated lesions with } \\
\text { high T2 signal } \\
\text {-Fluid-fluid level may be present }\end{array}$ & $\begin{array}{l}\text {-Ill-defined lesions with variable T2 signal } \\
\text { depending on venous vessel calibre } \\
\text {-Small }=\text { more solid with lower T2 signal } \\
\text {-Large }=\text { flow voids }\end{array}$ & $\begin{array}{l}\text {-Serpiginous flow voids representative } \\
\text { of arteries and draining veins }\end{array}$ \\
\hline US & $\begin{array}{l}\text {-Variable echogenicity depending on size } \\
\text { of cystic components }\end{array}$ & $\begin{array}{l}\text {-Mixed echogenicity components } \\
\text {-Slow monophasic venous flow }\end{array}$ & $\begin{array}{l}\text {-Enlarged feeding artery and dilated veins } \\
\text { with arterialised flow } \\
\text {-Stacked, biphasic waveform }\end{array}$ \\
\hline Site & $\begin{array}{l}\text {-Submandibular space } \\
\text {-Posterior cervical space }\end{array}$ & $\begin{array}{l}\text {-Deep neck spaces } \\
\text {-Maxilla or mandible }\end{array}$ & $\begin{array}{l}\text {-Rare in this region } \\
\text {-Usually involves lingual artery }\end{array}$ \\
\hline
\end{tabular}

homogenous high signal on T2-weighted images or rupture of the fibrous capsule [22].

\section{Nerve sheath tumours}

Schwannomas and neurofibromas are rare within the sublingual and submandibular spaces. Arising from peripheral and sympathetic nerves, schwannomas involving the lingual and hypoglossal nerves can occur in the floor of the mouth. Neurofibromas are associated with known neurofibromatosis. On CT, these lesions are described as enhancing homogenous isoattenuating masses with distinct margins. On MRI, they demonstrate isointense signal on T1weighted imaging and hyperintense signal on T2-weighted imaging, relative to the adjacent musculature. Larger lesions can have cystic components [13].

\section{Malignant neoplasms}

Malignant lesions within this region typically represent invasive squamous cell carcinoma originating in the mucosa of the floor of the mouth or the relatively rare primary salivary gland neoplasms, most commonly adenoid cystic carcinoma in submandibular gland and mucoepidermoid carcinoma in the parotid gland. Primarily evaluated on CT and MRI, these malignant processes are often indistinguishable on imaging, resembling infiltrative lesions with similar routes of spread including perineural and osseous extension (Figs. 14, 15, and 16) $[18,28]$. MRI helps in assessment of tumour extent, specifically defining depth of invasion, a critical component in the T-staging of oral cavity cancer [13, 29, 30].

Lymphoma of the salivary glands is rare, accounting for about 5\% of non-Hodgkin's lymphomas with mucosa-associated lymphoid tissue (MALT) lymphoma as the most common subtype. Salivary glands may acquire lymphocytes due to chronic inflammation or autoimmune disorder, such as Sjogren's syndrome or arise from intra-parotid lymph nodes. Imaging features typically mimic those of other lymphoproliferative disorders with homogeneously enhancing nodules on $\mathrm{CT}$, which demonstrate homogeneous intermediate signal on all MRI sequences [22, 31].
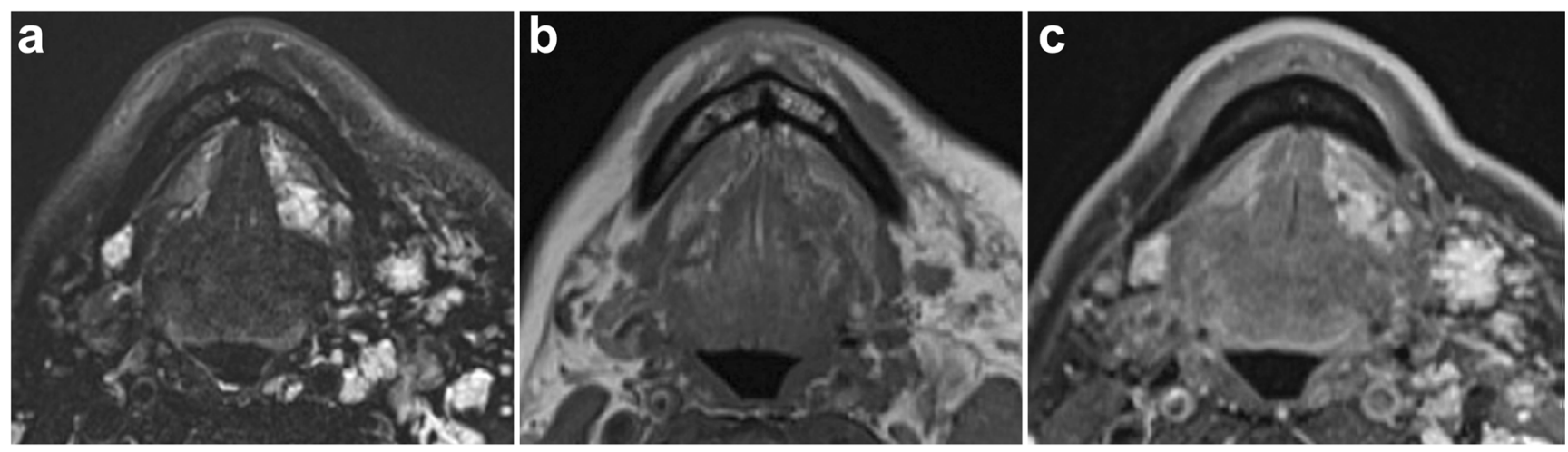

Fig. 12 Mixed veno-lymphatic malformation. a Axial T2-weighted MR image shows multiple trans-spatial high-signal lesions scattered predominantly throughout the left neck spaces, including the left sublingual space. b, $\mathbf{c}$ Pre- and post-contrast T1-weighted images show enhancement of these lesions 
Fig. 13 Pleomorphic adenoma of the submandibular gland. a Axial and $\mathbf{b}$ coronal contrast-enhanced $\mathrm{CT}$ images demonstrate an enhancing well-circumscribed round mass within the inferior aspect of the right submandibular gland (arrow)

Fig. 14 Squamous cell carcinoma involving the left sublingual space. Infiltrative lesion centred within the left sublingual space, which demonstrates heterogenous intermediate to high signal on T2weighted MRI (a) and isointensity compared with adjacent musculature on T1weighted MRI (b). c Post-contrast axial and $\mathbf{d}$ coronal T1-weighted MR images reveal heterogenous enhancement (arrow)

Fig. 15 Squamous cell carcinoma involving the left sublingual space. a Axial contrast-enhanced CT image shows a homogenously enhancing lesion within the left sublingual space (arrow), b which demonstrates ${ }^{18} \mathrm{~F}$ -

fluorodeoxyglucose (FDG) avidity on PET/CT
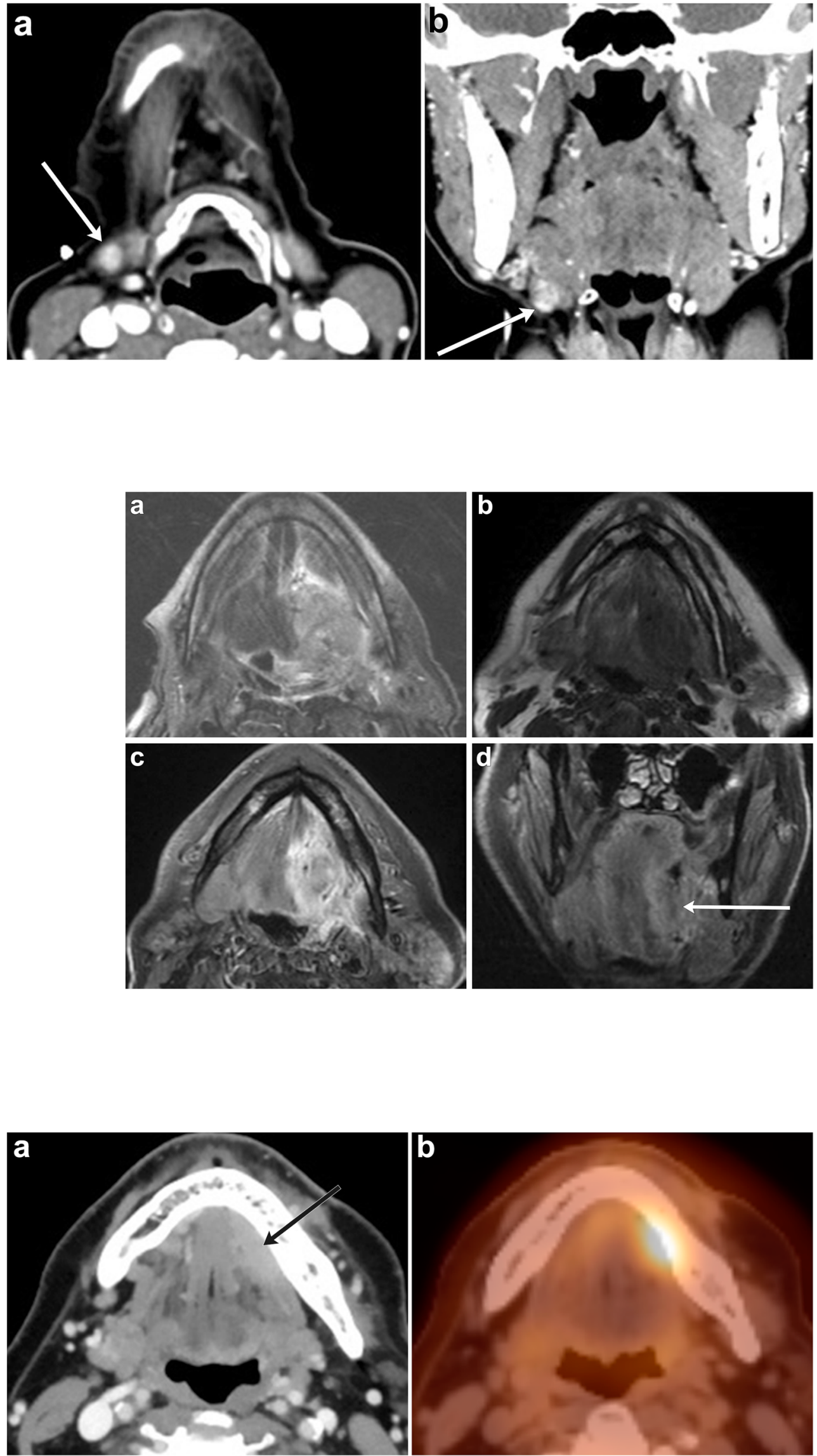

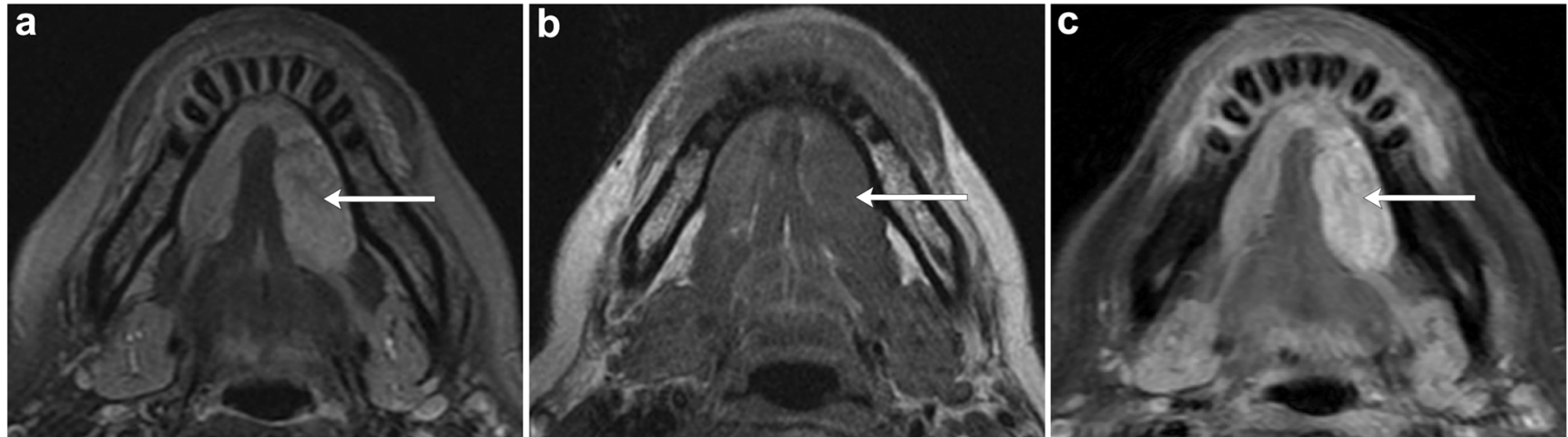

Fig. 16 Adenoid cystic carcinoma of the sublingual gland. a Axial T2weighted and b T1-weighted MR images of the sublingual space demonstrate a lobulated high T2 signal and low T1 signal lesion

\section{Pseudo-lesion}

\section{Mylohyoid defects with herniation of sublingual space contents}

The mylohyoid muscle is traditionally depicted as a continuous muscular sling formed from two halves that join at the fibrous median raphe. However, with modern day CT and MRI, focal defects are becoming increasingly evident and have been reported in up to $77 \%$ of CT studies. During embryological development, the anterior and posterior muscular sheets fail to overlap with a resultant slit, allowing for protrusion of the sublingual space contents into the submandibular space (Fig. 17). Also known as the mylohyoid boutonniere, the protruding salivary gland tissue, fat, blood vessels or a combination of the three can present as a palpable "mass" on physical exam (Fig. 18) [32].

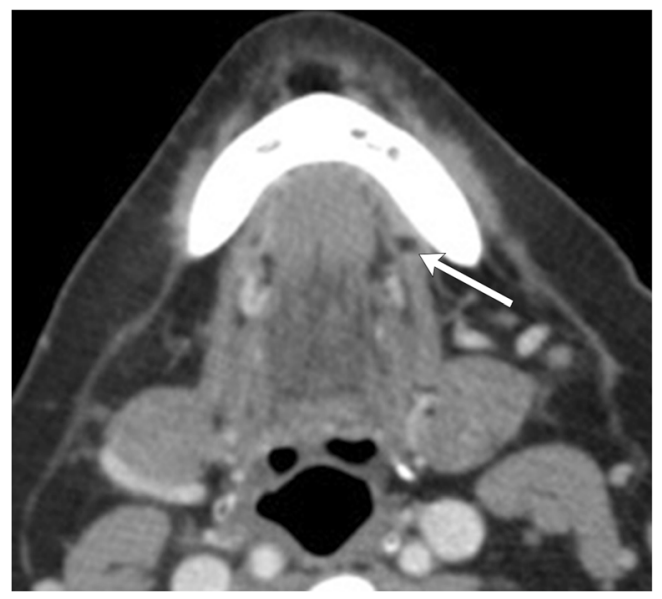

Fig. 17 Mylohyoid slit (boutonniere). Axial contrast-enhanced CT image shows a linear, fat-containing defect within the mylohyoid muscle at the anterior aspect (arrow) enlarging and distorting the left sublingual gland (arrow). c There is diffuse enhancement on the axial post-contrast T1-weighted MR image

\section{Sialosis}

Symmetrical, diffuse and painless enlargement of the sublingual and submandibular glands may reflect response to a systemic process, such as diabetes mellitus, hypothyroidism, chronic alcoholism, malnutrition and certain drugs such as antibiotics, diuretics and antipsychotics. Bilateral and symmetric involvement should clue one into the possibility of a systemic diagnosis [22].

\section{Conclusions}

As seen, a variety of pathology occurs within the sublingual and submandibular spaces, as well as the surrounding regions. Utilising knowledge of embryological origin of the tissues, anatomical relationships and characteristic im-

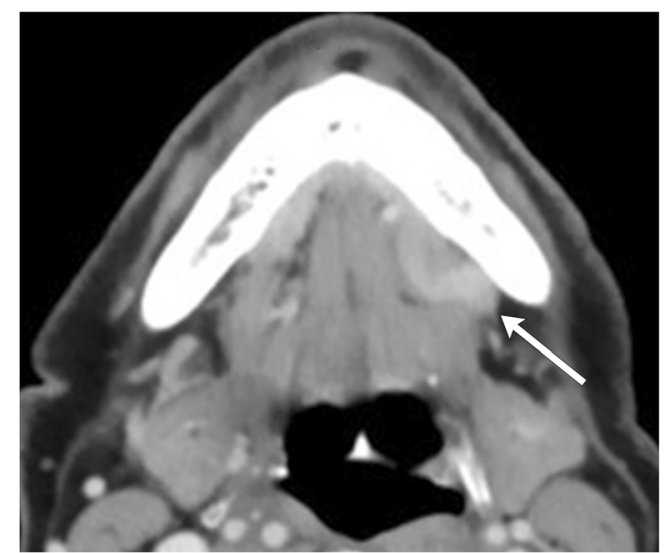

Fig. 18 Sublingual gland herniation, mimicking a palpable "lesion" on physical exam. Axial contrast-enhanced CT image demonstrates herniation of the left submandibular gland through a mylohyoid muscle sling defect 
aging features can help the radiologist in accurately diagnosing pathology.

Open Access This article is distributed under the terms of the Creative Commons Attribution 4.0 International License (http:// creativecommons.org/licenses/by/4.0/), which permits unrestricted use, distribution, and reproduction in any medium, provided you give appropriate credit to the original author(s) and the source, provide a link to the Creative Commons license, and indicate if changes were made.

\section{References}

1. Harnsberger HR (2011) Diagnostic imaging: head and neck, 2nd edn. Amirsys, Philadelphia

2. Yousem DM, Kraut MA, Chalian AA (2000) Major salivary gland imaging. Radiology 216:19-29. https://doi.org/10.1148/radiology. 216.1.r00j14519

3. Yilmaz MD, Yucel A, Derekoy S et al (2002) Unilateral aplasia of the submandibular gland. Eur Arch Otorhinolaryngol 259:554-556

4. Odeh M, Bronshtein M, Bornstein J (2017) Congenital absence of salivary glands in fetuses with trisomy 21. Isr Med Assoc J 19:12-14

5. Srinivasan A, Moyer JS, Mukherji SK (2006) Unilateral submandibular gland aplasia associated with ipsilateral sublingual gland hypertrophy. AJNR Am J Neuroradiol 27:2214-2216

6. Dillon JR, Avillo AJ, Nelson BL (2015) Dermoid cyst of the floor of the mouth. Head Neck Pathol 9:376-378. https://doi.org/10. 1007/s12105-014-0576-y

7. Jayasuriya NSS, Siriwardena S, Tilakaratne WM et al (2017) Malignant transformation of a long-standing submental dermoid cyst to a carcinosarcoma: a case report. J Med Case Rep 11:11. https://doi.org/10.1186/s13256-016-1186-y

8. Longo F, Maremonti P, Mangone GM et al (2003) Midline (dermoid) cysts of the floor of the mouth: report of 16 cases and review of surgical techniques. Plast Reconstr Surg 112:1560-1565. https://doi.org/10.1097/01.PRS.0000086735.56187.22

9. Wong KT, Lee YYP, King AD et al (2008) Imaging of cystic or cyst-like neck masses. Clin Radiol 63:613-622. https://doi.org/10. 1016/j.crad.2007.12.007

10. Fang WS, Wiggins RH, Illner A et al (2011) Primary lesions of the root of the tongue. Radiographics 31:1907-1922

11. Vogl TJ, Stegler W, Ihrler S et al (1993) Cystic masses in the floor of the mouth: value of MR imaging in planning surgery. AJR Am J Roentgenol 161:183-186

12. Kurabayashi T, Nakamura S, Ogura I et al (2003) The sublingual and submandibular spaces. Oral Radiol 19:28-34

13. La'Porte SJ, Juttla JK, Lingam RK (2011) Imaging the floor of the mouth and the sublingual space. Radiographics 31:1215-1230

14. Gaddikeri S, Vattoth S, Gaddikeri R et al (2014) Congenital cystic neck masses: embryology and imaging appearances, with clinicopathological correlation. Curr Probl Diagn Radiol 43:55-67. https:// doi.org/10.1067/j.cpradiol.2013.12.001

15. Meesa IR, Srinivasan A (2015) Imaging of the oral cavity. Radiol Clin N Am 53:99-114
16. Kurabayashi T, Ida M, Yasumoto M et al (2000) MRI of ranulas. Neuroradiology 42:917-922

17. Yousem DM, Chalian AA (1998) Oral cavity and pharynx. Radiol Clin N Am 36:967-981

18. Agarwal AK, Kanekar SG (2012) Submandibular and sublingual spaces: diagnostic imaging evaluation. Otolaryngol Clin N Am 45: 1311-1323. https://doi.org/10.1016/j.otc.2012.08.005

19. Branstetter BF, Weissman JL (2003) Infection of the facial area, oral cavity, oropharynx, and retropharynx. Neuroimaging Clin N Am 13:393-410

20. Capps EF, Kinsella JJ, Gupta M et al (2010) Emergency imaging assessment of acute, nontraumatic conditions of the head and neck. Radiographics 30:1335-1352

21. Jäger L, Menauer F, Holzknecht N et al (2000) Sialolithiasis: MR sialography of the submandibular duct - an alternative to conventional sialography and US? Radiology 216:665-671

22. Rastogi R, Bhargava S, Mallarajapatna GJ et al (2012) Pictorial essay: salivary gland imaging. Indian J Radiol Imaging 22:325-333

23. Mandel L (2014) Salivary gland disorders. Med Clin N Am 98: 1407-1449. https://doi.org/10.1016/j.mcna.2014.08.008

24. Rinast E, Gmelin E, Hollands-Thorn B (1989) Digital subtraction sialography, conventional sialography, high-resolution ultrasonography and computed tomography in the diagnosis of salivary gland diseases. Eur J Radiol 9:224-230

25. Kalinowski M, Heverhagen JT, Rehberg E et al (2002) Comparative study of MR sialography and digital subtraction sialography for benign salivary gland disorders. AJNR Am J Neuroradiol 23:1485-1492

26. Donnelly LF, Adam DM, Bisset GS (2000) Vascular malformations and hemangiomas: a practical approach in a multidisciplinary clinic. AJR Am J Roentgenol 174:597-608

27. Baer AH, Parmar HA, DiPietro MA et al (2011) Hemangiomas and vascular malformations of the head and neck: a simplified approach. Neuroimaging Clin N Am 21:641-658. https://doi.org/10. 1016/j.nic.2011.05.007

28. Lenz M, Greess H, Baum U et al (2000) Oropharynx, oral cavity, floor of the mouth: CT and MRI. Eur J Radiol 33:203-215

29. Ozturk M, Yorulmaz I, Gunet E et al (2000) Masses of the tongue and floor of the mouth: findings on magnetic resonance imaging. Eur Radiol 10:1669-1674

30. Lydiatt WM, Patel SG, O'Sullivan B et al (2017) Head and neck cancers-major changes in the American joint committee on cancer eighth edition cancer staging manual. Cancer J Clin 67:122-137. https://doi.org/10.3322/caac.21389

31. Kato H, Kanematsu M, Goto H et al (2012) Mucosa-associated lymphoid tissue lymphoma of the salivary glands: MR imaging findings including diffusion-weighted imaging. Eur J Radiol 81: 612-617

32. White DK, Davidson HC, Harnsberger HR et al (2001) Accessory salivary tissue in the mylohyoid boutonniere: a clinical and radiologic pseudolesion of the oral cavity. AJNR Am J Neuroradiol 22: 406-412

\section{Publisher's Note}

Springer Nature remains neutral with regard to jurisdictional claims in published maps and institutional affiliations. 